\title{
Reply to Theeuwes: Fast Feature-based Top-down Effects, but Saliency May be Slow
}

\author{
Stefanie I. Becker \\ School of Psychology, The University of Queensland, Brisbane, AU \\ s.becker@psy.uq.edu.au
}

Keywords: Attention; Eye movements; Visual search

In this review paper, Theeuwes (2018) continues to defend his view that (1) many effects previously believed to reflect top-down processes are in fact bottom-up/stimulus-driven, and (2) that top-down processes play a role only at a later stage of processing. This view contrasts with current models of attention, which commonly assume that both bottom-up, saliency-based processes and top-down, feature-based processes influence early processes. In these models, top-down selection is assumed to occur via the modulation of sensory neurons (organized in feature maps) that respond to specific elementary features (e.g., red, or tilted; e.g., Wolfe, 1994; Navalpakkam \& Itti, 2007). Specifically, the intention to find a specific target such as a red item selectively increases the signals of all red items so that they have the highest activation in the attention guiding priority map (e.g., Wolfe, 1994). Importantly, this gain increase occurs in response to an expectation or intention, and can precede the appearance of the target (e.g., Kastner et al., 1999). With this, top-down processes modulate neurons at a very early point in time, even before a stimulus appears.

With regard to these models, it seems that Theeuwes does not deny that feature-specific neurons can modulate selection, but he implies that it is impossible to modulate these neurons 'at will' (prior to selecting the item). Instead, he maintains that (1) most feature-based effects are effects of the selection history (e.g., priming effects), and (2) that these priming effects occur automatically and are impervious to top-down control.

However, in an eye movement study, Becker, Ansorge and Horstmann (2009) showed that priming can only account for a small portion of top-down selectivity for the target (i.e., $28 \mathrm{~ms}$ of a $76 \mathrm{~ms}$ effect). Moreover, priming effects usually display 'contingent automaticity' in that they are (1) stronger or only present for task-relevant features of the target (e.g., Becker, 2010) and (2) are smaller or eliminated when participants know that the next target will have a different feature (e.g., Folk \& Remington, 2008; Fecteau, 2007). So it is neither the case that priming can fully explain top-down feature-based effects, nor that priming is impervious to top-down control. Admittedly there are experiments that show no or only negligible effects of top-down knowledge (e.g., Belopolsky et al., 2010). Still, we have to keep in mind that participants do not always follow optimal strategies (e.g., Irons \& Leber, 2016), and that experiments can only inform us about what people do and don't do - not necessarily about what they can and can't do.

A second set of studies that Theeuwes frequently cites to argue for 'fast bottom-up and late top-down selection' are studies where eye movement latencies are used to track the dynamic activation pattern on the priority map. For example, in a visual search task for a coloured (e.g., red) target, Mulckhuyse, van Zoest and Theewues (2008) measured the onset latency of eye movements to different types of irrelevant distractors. The typical finding is that the $20 \%$ fastest eye movements to a salient, target-dissimilar distractor (e.g., green) occur earlier in time (with a latency of $\sim 130 \mathrm{~ms}$ ) than the $20 \%$ fastest eye movements to the target-similar distractor (e.g., red; $\sim 140 \mathrm{~ms}$; see Figure 1B). From this it is then concluded that saliency signals dominate selection at an early stage of visual search and that top-down control enters search only at a later stage.

Becker, Lewis and Axtens (2017) however criticised that this research question requires an analysis that considers both the timing of eye movements and the proportion of eye movements to each distractor (as there are typically far fewer eye movements to the target-dissimilar distractor than the similar distractor). When both of these factors are considered, the results show that all eye movements, including the earliest ones, are more likely to be directed to the target-similar distractor than a target-dissimilar distractor, without any 


\section{A) New: Latencies and Proportions}

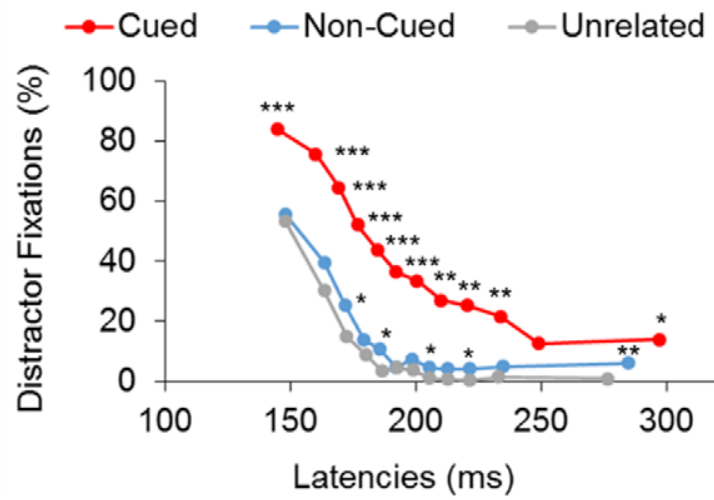

B) Latency Analysis as in Mulckhuyse et al.

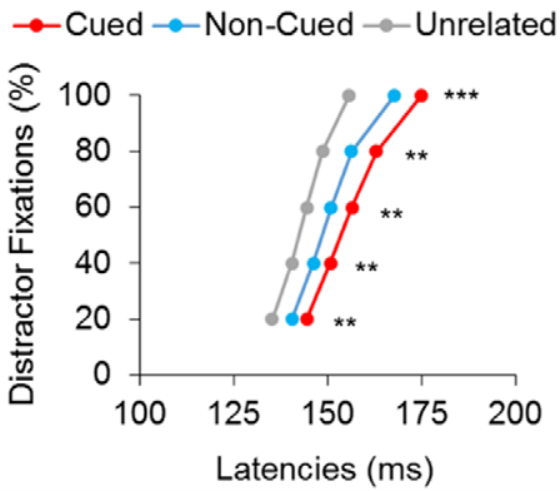

Figure 1: (A) The proportion and latencies of first eye movements to distractors that matched a word-cue announcing the target colour (Cued), mismatched the word cue but had a possible target colour (Noncued) and distractors with a non-target colour (Unrelated). There were no differences in the timing of the $8 \%$ fastest saccades (12 bins), but a higher proportion of eye movements to the distractor that had the upcoming target colour. (B) Analysing the data in the same way as in Mulckhuyse et al., showed the typical results pattern of longer latencies for the earliest $20 \%$ of saccades to the cued distractor than to the nonmatching or unrelated distractor (due to the fact that the distribution of the cued distractor has a longer tail; see Becker et al., 2017, Exp. 2).

differences in the timing of early eye movements (see Figure $\mathbf{1 A}$ for an illustration). In a second experiment, Becker et al., randomly varied the target colour (e.g., between red and green) and used a word cue to announce the target colour on the next trial (e.g., "RED"). The results showed significantly higher selection rates of distractors matching the word cue than other distractors, including in the earliest eye movements (see Figure 1A, B). These results could not be explained by priming effects, demonstrating that top-down knowledge dominates selection at an early stage (and over the entire time-course of selection). Here then is an example of a study that used the same procedures as Theeuwes and colleagues and demonstrates (with a slightly different analysis) that top-down knowledge modulates early visual selection.

Interestingly and contrary to Theeuwes, saliency-based effects may not be purely bottom-up or early. One classical view is that stimuli with a high feature contrast enjoy a processing advantage because similarlooking items inhibit each other (via lateral inhibitory connections; e.g., Nakayama \& Martini, 2011). Apart from this passive bottom-up advantage of salient stimuli (which can be overridden by top-down intentions; e.g., Eimer \& Kiss, 2008), there is also some evidence that saliency may play a special role at later stages of visual processing.

In a recent EEG study, we found that a salient irrelevant distractor was not attended, yet could be recalled with higher accuracy than other non-salient distractors (Martin \& Becker, in revision). This suggests that the visual system has evolved later mechanisms to remember salient items with greater accuracy (e.g., by allowing singletons preferential access to awareness/VSTM). Salient items are potentially more informative or useful for the visual system because they can be used for efficient orienting and thus may enjoy a top-down advantage. While further research is necessary to confirm these findings, it is very well possible that saliency plays a more important role for late processes mediating awareness than for early processes, and that these are in part top-down or strategic (e.g., Benoni, 2018; Kiss et al., 2012). Hence, directly reversing Theeuwes' view on the timing and nature of top-down vs. bottom-up processes may yield a more accurate theory of attention and awareness than the currently prominent views.

\section{Competing Interests}

The author has no competing interests to declare.

\section{References}

Becker, S. I. (2010). The role of target-distractor relationships in guiding attention and the eyes in visual search. Journal of Experimental Psychology: General, 139, 247-265. DOI: https://doi.org/10.1037/ a0018808 
Becker, S. I., Ansorge, U., \& Horstmann, G. (2009). Can intertrial priming account for the similarity effect in visual search? Vision Research, 49, 1738-1756. DOI: https://doi.org/10.1016/j.visres.2009.04.001

Becker, S. I., Lewis, A. J., \& Axtens, J. E. (2017). Top-down knowledge modulates onset capture in a feedforward manner. Psychonomic Bulletin \& Review, 24, 436-446. DOI: https://doi.org/10.3758/ s13423-016-1134-2

Belopolsky, A. V., Schreij, D., \& Theeuwes, J. (2010). What is top-down about contingent capture? Attention, Perception, \& Psychophysics, 72, 326-341. DOI: https://doi.org/10.3758/APP.72.2.326

Benoni, H. (2018). Top-down prioritization of salient items may produce so-called stimulus-driven capture. Frontiers in Psychology. DOI: https://doi.org/10.3389/fpsyg.2018.00218

Eimer, M., \& Kiss, M. (2008). Involuntary attentional capture is determined by task set: Evidence from event-related brain potentials. Journal of Cogntive Neuroscience, 20, 1423-1433. DOI: https://doi. org/10.1162/jocn.2008.20099

Fecteau, J. H. (2007). Priming of pop-out depends upon the current goals of observers. Journal of Vision, 7 , 1-11. DOI: https://doi.org/10.1167/7.6.1

Folk, C. L., \& Remington, R. W. (2008). Bottom-up priming of top-down attentional control settings. Visual Cognition, 16, 215-231. DOI: https://doi.org/10.1080/13506280701458804

Irons, J. L., \& Leber, A. B. (2016). Choosing attentional control settings in a dynamically changing environment. Attention, Perception, \& Psychophysics, 78, 2031-2048. DOI: https://doi.org/10.3758/ s13414-016-1125-4

Kastner, S., Pinsk, M. A., De Weerd, P., Desimone, R., \& Ungerleider, L. G. (1999). Increased activity in human visual cortex during directed attention in the absence of visual stimulation. Neuron, 22, 751-761. DOI: https://doi.org/10.1016/S0896-6273(00)80734-5

Kiss, M., Grubert, A., Petersen, A., \& Eimer, M. (2012). Attentional capture by salient distractors during visual search is determined by temporal task demands. Journal of Cognitive Neuroscience, 24, 749-759. DOI: https://doi.org/10.1162/jocn_a_00127

Martin, A., \& Becker, S. I. (in revision). How feature relationships influence attention and eye movements: Evidence from eye movements and EEG. Journal of Experimental Psychology: Human Perception and Performance.

Mulckhuyse, M., Van Zoest, W., \& Theeuwes, J. (2008). Capture of the eyes by relevant and irrelevant onsets. Experimental Brain Research, 186, 225-235. DOI: https://doi.org/10.1007/s00221-007-1226-3

Navalpakkam, V., \& Itti, L. (2007). Search goal tunes visual features optimally. Neuron, 53, 605-617. DOI: https://doi.org/10.1016/j.neuron.2007.01.018

Theeuwes, J. (2018). Visual Selection: Usually Fast and Automatic; Seldom Slow and Volitional. Journal of Cognition, 1(1), 29. DOI: http://doi.org/10.5334/joc.13

Wolfe, J. M. (1994). Guided Search 2.0: A revised model of visual search. Psychonomic Bulletin \& Review, 1, 202-238. DOI: https://doi.org/10.3758/BF03200774

\footnotetext{
How to cite this article: Becker, S. I. 2018 Reply to Theeuwes: Fast Feature-based Top-down Effects, but Saliency May be Slow. Journal of Cognition, 1(1): 28, pp.1-3, DOl: https://doi.org/10.5334/joc.23

Submitted: 06 March 2018 Accepted: 15 March 2018 Published: 14 May 2018

Copyright: (c) 2018 The Author(s). This is an open-access article distributed under the terms of the Creative Commons Attribution 4.0 International License (CC-BY 4.0), which permits unrestricted use, distribution, and reproduction in any medium, provided the original author and source are credited. See http://creativecommons.org/ licenses/by/4.0\%

] $\mathrm{u}\left[\begin{array}{l}\text { Journal of Cognition is a peer-reviewed open access journal published by Ubiquity } \\ \text { Press. }\end{array}\right.$ 